\section{Kidney \\ Blood Pressure \\ Research}

\title{
Gender Difference in the Association of Hyperuricemia with Chronic Kidney Disease in Southern China
}

\author{
Zhibin Lia,b,e Qinghua Liu ${ }^{a, e}$ Haiping Mao ${ }^{a}$ Zhijian Lia Xiuqing Dong ${ }^{a}$ \\ Yongwen Liua Jianxiong Lin ${ }^{a}$ Weiqing Chenc Hui Wang ${ }^{c}$ Richard J. Johnson ${ }^{d}$ \\ Xueqing $\mathrm{Yu}^{\mathrm{a}}$ Wei Chen ${ }^{\mathrm{a}}$
}

aDepartment of Nephrology, The First Affiliated Hospital, Sun Yat-sen University, Guangzhou, China \& Key Laboratory of Nephrology, Ministry of Health, China, ${ }^{b}$ Epidemiology Research Unit, Translational Medicine Research Center, The First Affiliated Hospital, Sun Yat-sen University, Guangzhou, China, 'Department of Epidemiology and Preventive Medicine, School of Public Health, Sun Yat-sen University, Guangzhou, China, 'Division of Renal Diseases and Hypertension, University of Colorado Denver, Aurora, CO 80045, USA, eZhibin Li and Qinghua Liu have contributed equally to this study

\section{Key Words}

Hyperuricemia $•$ Chronic kidney disease $•$ Gender $•$ Epidemiology

\begin{abstract}
Background: The effect of hyperuricemia on chronic kidney disease (CKD) is controversial, and little is known about gender as it relates to hyperuricemia and CKD. Methods: This was a cross-sectional study of 7,053 adults in the general Chinese population in Southern China using a multi-stage stratified sampling method. In which associations between hyperuricemia and indicators of CKD (defined by albuminuria (urinary albumin-to -creatinine ratio $\geq 30 \mathrm{mg} / \mathrm{g}$ ) or decreased modified MDRD equation estimated GFR $\left(<60 \mathrm{ml} / \mathrm{min}\right.$ per $\left.1.73 \mathrm{~m}^{2}\right)$ were tested using multivariate logistic regression. Results: After adjustment for potential confounders, hyperuricemia was associated with increased risk of reduced renal function and CKD but not albuminuria, with odds ratios (ORs) $(95 \%$ CI) of 4.39 (3.38-5.70, $P<0.001), 1.54$ (1.31-1.82, $P<0.001)$ and $0.96(0.78-1.17, P=0.671)$, respectively. The interaction between gender and hyperuricemia with CKD was significant $(P=0.010)$; and stratified analysis showed a stronger association of hyperuricemia with CKD in males (OR (95\% CI): $2.04(1.56-2.67), P<0.001)$ than in females (1.45 (1.17-1.80), $P=0.001)$. Conclusions: We observed an independent association of hyperuricemia with CKD that was stronger in males, and this independent association in male might imply some gender specific mechanisms. These results should be confirmed in future prospective studies.
\end{abstract}




\section{Kidney Blood Pressure Research}

Li/Liu/Mao/Li/Dong/Liu/Lin/Chen/Wang/Johnson/Yu/Chen: Gender, Hyperuricemia and CKD

\section{Introduction}

Chronic kidney disease (CKD) is increasing worldwide, and is a major public health problem [1]. The prevalence rate of CKD in China varies between 10.8\% and 19\% [2-5]. Identifying modifiable risk factors of CKD may elucidate preventive strategies. Hyperuricemia is associated with confirmed CKD risk factors such as hypertension and diabetes [6]. However, the relationship of hyperuricemia with CKD has been controversial, with some studies reporting that hyperuricemia is an independent risk factor of incident CKD [7-11] but others showing no statistically significant relationship between hyperuricemia and incident CKD [12]. Furthermore, little is known about gender difference as it relates to hyperuricemia and CKD.

We examined the independent association between hyperuricemia and CKD in a cross-sectional study of 7053 general adults in southern China and investigated the gender interaction in this relation.

\section{Subjects and Methods}

\section{Study population}

A cross-sectional study of CKD and associated risk factors in the general adult population in urban city of Guangzhou and rural area of Zhuhai in Guangdong province (southern China) was conducted from July 2006 to June 2007. Subjects were local residents aged 20 years or older who had lived in the region for at least 5 years. Subject sampling, recruitment and evaluation have been described previously [3]. Briefly, twelve communities in Guangzhou and 4 villages in Zhuhai were randomly selected using a multistage, stratified sampling method. Then, a simple randomized method was used to select households from the chosen communities or villages, and all subjects fulfilling the inclusion criteria were selected. Lastly, 6311 subjects in Guangzhou and 1214 subjects in Zhuhai were enrolled into this study (total of 7525 subjects). Of these participants, 7053 (93.7\%) subjects completed the entire survey. Both Guangzhou and Zhuhai are two major big cities in Guangdong province in southern China, people living there have similar life styles, and there is no statistical significance in demographic and socioeconomic characteristics between these two cities (data not shown). We selected the urban citizens of Guangzhou city and the rural population of Zhuhai city as the representative sample population from southern China, and when we pooled the 7053 subjects for the statistical analyses, the city of residence was still considered as a potential confounding factor in the multivariate regression analysis. The study was approved by the Human Ethics Committees of Sun Yat-sen University (Guangzhou, China). Written informed consent was obtained from all participants.

\section{Measurements}

Screening protocol and evaluation criteria were described previously [3]. Staffs in this study were doctors and medical students, who received intensive training in epidemiologic screening methods. Data were collected at local health stations or community clinics. The standard questionnaire was used during the face-to-face interview to collect socio-demographic status, lifestyle habits, health history and medications for each subject. Anthropometric measurements were obtained using standard protocols and techniques. After removal of shoes and heavy clothing, each subject underwent weight, height and waist measurements, using a calibrated scale. Body mass index (BMI) was calculated as weight in kilograms divided by height squared in squared meters. A fasting venous blood sample was collected for measuring various biomarkers. A clean-catch, midstream, morning urine specimen was collected for dipstick urinalysis (Roche Diagnostics, Mannheim, Germany) and microscopic analysis at the local survey site. All blood and urine samples were refrigerated at $-20^{\circ} \mathrm{C}$, transferred and tested in the laboratory of the First Affiliated Hospital, Sun Yat-sen University. Urinary albumin and creatinine were measured on a morning urine sample using an automatic analyzer (COBAS INTEGRA 400 plus, Roche, Basel, Switzerland). Urinary creatinine was measured by Jaffe's kinetic method, and albuminuria was measured by immunoturbidimetric methods. Urinary albumin-tocreatinine ratio (ACR, milligram per gram) was calculated. Microalbuminuria and macroalbuminuria were defined according to the guideline of American Diabetes Association as an increase in ACR between 30 and $299 \mathrm{mg} / \mathrm{g}$ and $300 \mathrm{mg} / \mathrm{g}$ or over, respectively. 


\section{Kidney \\ Blood Pressure Research}

Kidney Blood Press Res 2012;36:98-106

\begin{tabular}{l|l}
\hline DOI: $10.1159 / 000341486$ & (c) 2012 S. Karger AG, Basel
\end{tabular}

Published online: August 29, 2012

www.karger.com/kbr

i/Liu/Mao/Li/Dong/Liu/Lin/Chen/Wang/Johnson/Yu/Chen: Gender, Hyperuricemia and CKD

Serum uric acid was measured by the auto-analyzer (COBAS INTEGRA 400 plus, Roche, Basel, Switzerland). Serum creatinine (Scr) was measured using the same method as that for urinary creatinine. Before the study, the laboratory in our center calibrated serum creatinine measurements with samples at the laboratory of the Peking University First Hospital, where the modified equation was developed $[3,13]$. Estimated glomerular filtration rate (eGFR) was calculated using a modification of the Modification of Diet in Renal Disease (MDRD) equation based on the data from Chinese subjects with CKD [13], defined as eGFR $\left(\mathrm{mL} / \mathrm{min} / 1.73 \mathrm{~m}^{2}\right)=175 \times \mathrm{Scr}(\mathrm{mg} / \mathrm{dL})^{-1.234} \times$ age $(\text { year })^{-0.179}$ [female $\times 0.79$ ]

Serum fasting blood glucose, total cholesterol, low-density lipoprotein (LDL) cholesterol, high-density lipoprotein (HDL) cholesterol, and triglyceride were measured by auto-analyzer (COBAS INTEGRA 400 plus, Roche, Basel, Switzerland). Diabetes was defined as the use of insulin or oral hypoglycaemic agents or a fasting plasma glucose $\geq 7 \mathrm{mmol} / \mathrm{L}$, and/or 2-h postprandial plasma glucose $\geq 11.1 \mathrm{mmol} / \mathrm{L}$. Hyperlipidemia was defined as the presence of either hypercholesterolemia (serum total cholesterol $\geq 5.72 \mathrm{mmol} / \mathrm{L}$ ) or hypertriglyceridemia (serum triglyceride $\geq 1.70 \mathrm{mmol} / \mathrm{L}$ ). Arterial blood pressure was measured with a mercury sphygmomanometer after sitting for at least 15 minutes. Blood pressure measurements were taken according to the Joint National Committee VII criteria (JNC VII) [14]. Three readings were taken at 5-min intervals. The mean of the three measurements was recorded. Hypertension was defined as systolic blood pressure (SBP) $\geq 140 \mathrm{mmHg}$ or diastolic blood pressure (DBP) $\geq 90 \mathrm{mmHg}$, or self-reported diagnosis of high blood pressure and use of antihypertensive medication [14].

\section{Definitions of Hyperuricemia and Chronic Kidney Disease}

Hyperuricemia was defined as the serum uric acid level $>7.0 \mathrm{mg} / \mathrm{dL}$ in males and $>6.0 \mathrm{mg} / \mathrm{dL}$ in females [15]. CKD was defined as the presence of either decreased estimated GFR or albuminuria [1]. Albuminuria was defined as the presence of either microalbuminuria (urinary albumin-to-creatinine ratio (ACR) between 30 and $299 \mathrm{mg} / \mathrm{g}$ ) or macroalbuminuria (ACR greater than $300 \mathrm{mg} / \mathrm{g}$ ). Reduced renal function was defined as an $\mathrm{eGFR}<60 \mathrm{ml} / \mathrm{min} / 1.73 \mathrm{~m}^{2}$.

\section{Statistical Analysis}

Data entry and management were performed using Epidata software, version 3.0 (Epidata Association, Odense, Denmark). Data were presented as the mean \pm standard error for continuous variables and as proportions for categorical variables. Differences between subjects were analyzed using one way ANOVA for continuous variables and chi-square test for categorical variables. Multivariate logistic regression was used to calculate adjusted odds ratios (ORs) and 95\% confidence intervals (CI) of reduced renal function, albuminuria and CKD in different models with adjustment for the potential confounders. In model 1, city of residence, age, gender and educational level were adjusted for; in model 2, smoking and drinking habits were further adjusted for; finally, in model 3, BMI, hypertension, hyperlipidemia, diabetes and medications used were further adjusted for. To investigate whether there was significant gender difference in association between hyperuricemia and CKD, the interaction term between hyperuricemia and gender was tested. P $<0.05$ was considered significant. All statistical analyses were performed using SPSS version 17.0 (SPSS, Inc., Chicago, IL, USA).

\section{Results}

\section{Subject characteristics by gender}

Demographic, lifestyle characteristics of subjects by gender are shown in Table 1. Of the 7,053 participants, 4,726 (67.0\%) were female. The mean age $( \pm S D)$ of women and men were $50.5( \pm 12.4)$ years and $53.0( \pm 13.4)$ years, respectively. The crude prevalence of CKD was $13.7 \%$ in men and $10.4 \%$ in women. Male subjects had higher levels of educational attainment, and were more likely to smoke and drink than female subjects. Men were more likely to be suffered from hypertension, obesity, hyperlipidemia and diabetes when compared with women. Males had significantly higher level of serum uric acid (mean \pm SD: $397.1 \pm 91.6$ vs. 319.6 $\pm 84.8, \mathrm{P}<0.001$ ) than females. The prevalence rate of hyperuricemia was also significantly higher in men than in women ( $38.7 \%$ vs. $28.6 \%, \mathrm{P}<0.001)$. 


\section{Kidney \\ Blood Pressure Research}

Kidney Blood Press Res 2012;36:98-106

DOI: $10.1159 / 000341486$

Published online: August 29, 2012

(C) 2012 S. Karger AG, Basel

www.karger.com/kbr

Table 1. Demographic, lifestyle and clinical characteristics of subjects by gender

\begin{tabular}{|c|c|c|c|c|}
\hline Variables & Female & Male & Total & $P$ value \\
\hline \multicolumn{5}{|l|}{ Demographics } \\
\hline $\mathrm{N}(\%)$ & $4726(67.0 \%)$ & $2327(33.0 \%)$ & $7053(100.0 \%)$ & \\
\hline Age (years) & $50.5 \pm 12.4$ & $53.0 \pm 13.4$ & $51.3 \pm 12.8$ & $<0.001$ \\
\hline Education categories, \% & & & & $<0.001$ \\
\hline Illiteracy/Elementary school & $28.8 \%$ & $16.0 \%$ & $24.6 \%$ & \\
\hline Middle school & $29.2 \%$ & $27.9 \%$ & $28.8 \%$ & \\
\hline High school & $29.7 \%$ & $32.6 \%$ & $30.6 \%$ & \\
\hline College or above & $12.3 \%$ & $23.5 \%$ & $16.0 \%$ & \\
\hline \multicolumn{5}{|l|}{ Life style } \\
\hline Ever smoking, \% & $2.3 \%$ & $57.0 \%$ & $20.4 \%$ & $<0.001$ \\
\hline Ever drinking, \% & $3.0 \%$ & $27.3 \%$ & $11.0 \%$ & $<0.001$ \\
\hline \multicolumn{5}{|l|}{ Clinical characteristics } \\
\hline Systolic blood pressure(mmHg) & $123.8 \pm 20.9$ & $126.2 \pm 18.7$ & $124.6 \pm 20.2$ & $<0.001$ \\
\hline Diastolic blood pressure $(\mathrm{mmHg})$ & $78.5 \pm 10.6$ & $81.5 \pm 10.7$ & $79.5 \pm 10.7$ & $<0.001$ \\
\hline Hypertension, \% & $30.1 \%$ & $35.2 \%$ & $31.8 \%$ & $<0.001$ \\
\hline BMI $\left(\mathrm{kg} / \mathrm{m}^{2}\right)$ & $23.3 \pm 3.5$ & $23.7 \pm 3.2$ & $23.4 \pm 3.4$ & $<0.001$ \\
\hline Waist circumference $(\mathrm{cm})$ & $77.3 \pm 15.6$ & $82.4 \pm 9.2$ & $79.0 \pm 14.0$ & $<0.001$ \\
\hline Serum creatinine $(\mu \mathrm{mol} / \mathrm{L})$ & $58.7 \pm 12.2$ & $79.8 \pm 15.3$ & $65.6 \pm 16.6$ & $<0.001$ \\
\hline Cholesterol (mmol/L) & $5.8 \pm 1.2$ & $5.5 \pm 1.1$ & $5.6 \pm 1.2$ & $<0.001$ \\
\hline Triglyceride (mmol/L) & $1.4 \pm 1.0$ & $1.7 \pm 1.2$ & $1.5 \pm 1.1$ & $<0.001$ \\
\hline HDL & $1.6 \pm 0.4$ & $1.4 \pm 0.4$ & $1.6 \pm 0.5$ & $<0.001$ \\
\hline LDL & $3.6 \pm 1.0$ & $3.6 \pm 1.0$ & $3.6 \pm 1.0$ & 0.260 \\
\hline Hypercholesterolemia, \% & $44.9 \%$ & $40.4 \%$ & $43.4 \%$ & $<0.001$ \\
\hline Hyperlipidemia, \% & $53.6 \%$ & $56.1 \%$ & $54.4 \%$ & 0.045 \\
\hline Fasting blood glucose (mmol/L) & $5.5 \pm 1.4$ & $5.6 \pm 1.6$ & $5.6 \pm 1.5$ & 0.073 \\
\hline Diabetes Mellitus, \% & $9.2 \%$ & $10.6 \%$ & $9.6 \%$ & 0.060 \\
\hline Blood uric acid $(\mu \mathrm{mol} / \mathrm{L})$ & $319.6 \pm 84.8$ & $397.1 \pm 91.6$ & $345.2 \pm 94.4$ & $<0.001$ \\
\hline Hyperuricemia, \% & $28.6 \%$ & $38.7 \%$ & $31.9 \%$ & $<0.001$ \\
\hline $\begin{array}{l}\text { Reduced renal function } \\
\left(\mathrm{eGFR}<60 \mathrm{~mL} / \mathrm{min} / 1.73 \mathrm{~m}^{2}\right), \%\end{array}$ & $3.1 \%$ & $8.4 \%$ & $4.9 \%$ & $<0.001$ \\
\hline Albuminuria (ACR>30mg/g), \% & $8.1 \%$ & $6.9 \%$ & $7.8 \%$ & 0.073 \\
\hline CKD, \% & $10.4 \%$ & $13.7 \%$ & $11.5 \%$ & $<0.001$ \\
\hline
\end{tabular}

Subjects with missing data were excluded. All percentages are column percentage; except for percentages, all values are mean \pm s.d. Abbreviations: CKD, chornic kidney disease; BMI, body mass index; HDL, high-density lipoprotein cholesterol; LDL, low-density lipoprotein cholesterol.

Demographic and clinical characteristics according to presence of reduced eGFR, albuminuria or CKD

Differences in demographic and clinical characteristics of subjects stratified by presence of reduced eGFR, albuminuria and CKD are presented in Table 2. Increasing age and lower educational attainment were associated with significantly higher prevalence of reduced eGFR, albuminuria and CKD. A history of smoking was also associated with a higher 


\section{Kidney \\ Blood Pressure Research}

Table 2. Demographic, lifestyle and clinical characteristics of subjects by reduced renal function, albuminuria and CKD.

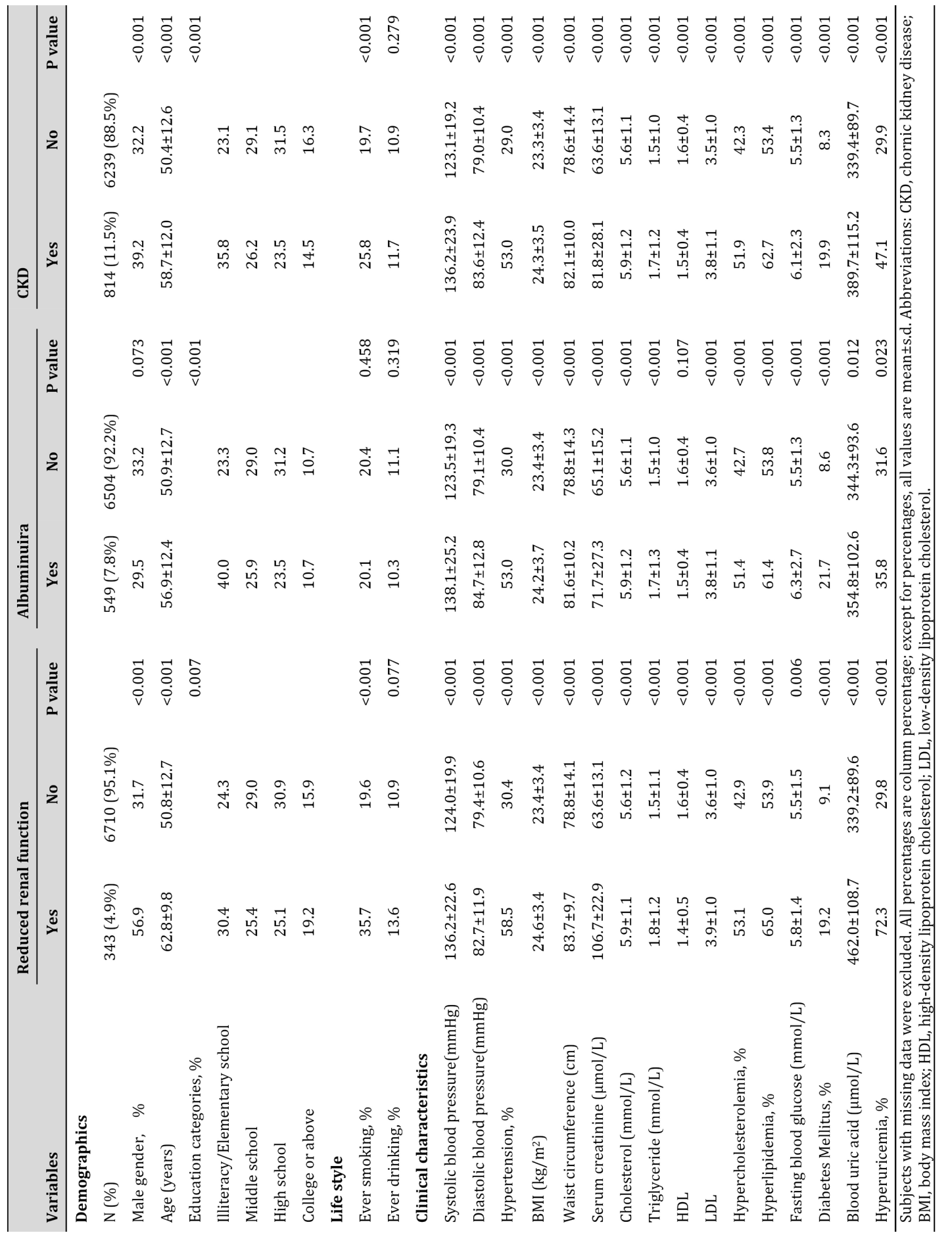

prevalence of reduced eGFR and CKD. Generally, subjects with reduced eGFR, albuminuria or CKD had significantly higher levels of BP, BMI, cholesterol, triglyceride, fasting blood glucose and blood uric acid, as well as higher prevalence of hypertension, obesity, hyperlipidemia, diabetes mellitus and hyperuricemia, as compared with subjects without these conditions. 


\section{Kidney \\ Blood Pressure Research}

Table 3. Adjusted odds ratios (ORs) with associated 95\% confidence interval (CI) for reduced renal function, albuminuira and CKD

\begin{tabular}{|c|c|c|c|c|c|c|c|c|c|}
\hline \multirow[b]{2}{*}{ Variables } & \multicolumn{3}{|c|}{ Reduced renal function } & \multicolumn{3}{|c|}{ Albuminuira } & \multicolumn{3}{|c|}{ CKD } \\
\hline & OR & $95 \% \mathrm{CI}$ & $P$ value & OR & $95 \% \mathrm{CI}$ & $P$ value & OR & $95 \% \mathrm{CI}$ & $P$ value \\
\hline \multicolumn{10}{|l|}{ Model 1} \\
\hline Gender (male vs. female) & $2.49^{* * *}$ & $1.94-3.19$ & $<0.001$ & $0.79 *$ & $0.64-0.97$ & 0.027 & $1.23^{*}$ & $1.04-1.45$ & 0.014 \\
\hline Hyperuricemia (yes vs. no) & $4.57^{* * *}$ & $3.54-5.90$ & $<0.001$ & 1.03 & $0.85-1.26$ & 0.749 & $1.63^{* * *}$ & $1.40-1.94$ & $<0.001$ \\
\hline Gender*Hyperuricemia & & & 0.388 & & & 0.651 & & & 0.019 \\
\hline \multicolumn{10}{|l|}{ Model 2} \\
\hline Gender (male vs. female) & $2.23^{* * *}$ & $1.64-3.04$ & $<0.001$ & $0.74^{*}$ & $0.56-0.98$ & 0.035 & 1.12 & $0.90-1.39$ & 0.296 \\
\hline Hyperuricemia (yes vs. no) & $4.62^{* * *}$ & $3.58-5.97$ & $<0.001$ & 1.03 & $0.85-1.26$ & 0.737 & $1.64^{* * *}$ & $1.40-1.92$ & $<0.001$ \\
\hline Gender*Hyperuricemia & & & 0.455 & & & 0.628 & & & 0.014 \\
\hline \multicolumn{10}{|l|}{ Model 3} \\
\hline Gender (male vs. female) & $2.28^{* * *}$ & $1.67-3.11$ & $<0.001$ & 0.76 & $0.57-1.01$ & 0.055 & 1.15 & $0.92-1.43$ & 0.216 \\
\hline Hyperuricemia (yes vs. no) & $4.39^{* * *}$ & $3.38-5.70$ & $<0.001$ & 0.96 & $0.78-1.17$ & 0.671 & $1.54^{* * *}$ & $1.31-1.82$ & $<0.001$ \\
\hline Gender*Hyperuricemia & & & 0.474 & & & 0.549 & & & 0.010 \\
\hline
\end{tabular}

Table 4. Adjusted odds ratios (ORs) with associated 95\% confidence interval $(\mathrm{CI})$ of hyperuricemia for CKD stratified by gender

\begin{tabular}{lcccccccc}
\hline & \multicolumn{3}{c}{ Female } & & \multicolumn{3}{c}{ Male } \\
\cline { 2 - 4 } \cline { 7 - 9 } Variables & OR & $95 \% \mathrm{CI}$ & P value & & OR & $95 \% \mathrm{CI}$ & P value \\
\hline Model 1 & $1.63^{* * *}$ & $1.33-2.00$ & $<0.001$ & & $2.04^{* * *}$ & $1.59-2.61$ & $<0.001$ \\
Model 2 & $1.64^{* * *}$ & $1.34-2.01$ & $<0.001$ & & $2.05^{* * *}$ & $1.60-2.64$ & $<0.001$ \\
Model 3 & $1.45^{* *}$ & $1.17-1.80$ & 0.001 & & $2.04^{* * *}$ & $1.56-2.67$ & $<0.001$ \\
\hline
\end{tabular}

Model 1 was adjusted for city of residence, age and educational level. Model 2 was adjusted for city of residence, age, educational level, ever smoking and ever drinking. Model 3 was adjusted for city of residence, age, educational level, ever smoking, ever drinking, blood pressure category, BMI, hypertension, hyperlipidemia, diabetes and medications. ${ }^{* *} \mathrm{p}<0.01,{ }^{* * *} \mathrm{p}<0.001$

\section{Association between hyperuricemia and CKD}

Adjusted odds ratios (ORs) with 95\% confidence intervals (CIs) of gender and hyperuricemia for reduced renal function, albuminuira and CKD are shown in Table 3. In model 1 (adjustment for city of residence, age, and educational level), males were more likely to suffer from reduced renal function (OR (95\% CI): 2.49 (1.94-3.19), $\mathrm{P}<0.001$ ) and CKD (1.23 (1.04-1.45), $\mathrm{P}=0.014)$, but were less likely to have albuminuria (0.79 (0.640.97), $\mathrm{P}=0.027)$ compared to females. Hyperuricemia was associated with increased OR for reduced renal function (4.57 (3.54-5.90), $\mathrm{P}<0.001)$ and CKD $(1.63(1.40-1.94), \mathrm{P}<0.001)$ but not albuminuria (1.03 (0.85-1.26), $\mathrm{P}=0.749)$.

In model 2 (which included additional adjustments for histories of smoking and alcohol drinking) and model 3 (with additional adjustments for BMI, hypertension, hyperlipidemia, diabetes and medications), the results were similar to those in model 1. Hyperuricemia was significantly associated with increased risk for reduced renal function and CKD; however, male gender was associated with increased risk of reduced renal function only but not albuminuria or CKD.

Gender difference in the association of hyperuricemia with CKD

An interaction between gender and hyperuricemia was identified for all three models for CKD ( $\mathrm{P}=0.019$ in model $1, \mathrm{P}=0.014$ in model 2 , and $\mathrm{P}=0.010$ in model 3 ) but not for reduced renal function or albuminuria, documenting that the association between hyperuricemia and CKD was different for male and females (Table 3).

Stratified analyses of the association between hyperuricemia and CKD by gender are shown in Table 4. All three models showed that the association of hyperuricemia with CKD 


\section{Kidney \\ Blood Pressure Research}

Kidney Blood Press Res 2012;36:98-106

\begin{tabular}{l|l}
\hline DOI: $10.1159 / 000341486$ & (C) 2012 S. Karger AG, Basel
\end{tabular}

Published online: August 29, 2012

www.karger.com $/ \mathrm{kbr}$

in males was significantly stronger than that in females, with adjusted ORs for CKD of 2.04 $(1.56-2.67, \mathrm{P}<0.001)$ and $1.45(1.17-1.80, \mathrm{P}=0.001)$, respectively (model 3).

\section{Discussion}

We found that hyperuricemia was independently associated with increased risk of reduced renal function and CKD but not albuminuria. Furthermore, there was a statistically significant interaction between gender and hyperuricemia on CKD; and the stratified analysis showed the association of hyperuricemia with CKD in males was significantly stronger than in females.

Although hyperuricemia is associated with the confirmed CKD risk factors such as hypertension and diabetes [6], the independent effect of hyperuricemia on CKD is controversial. Most epidemiologic studies have found that hyperuricemia is an independent risk factor for the onset of CKD, while the associations of hyperuricemia with declined eGFR or increased ESRD is supported by several cohort studies [7-10,12, 16-19], but not all $[20,21]$. Hsu et a l. found that increased serum uric acid is an independent risk factor for ESRD over a 25 year follow-up period evaluated in a cohort of 177,570 participants [18]. However, the data of 840 participants in the MDRD Study did not confirm that uric acid levels to be an independent risk factor for progression to ESRD despite a 10 year followup [20]. In the present cross-sectional study we found that hyperuricemia was associated with reduced eGFR but not with albuminuria. A similar observation was noted in subjects with type 1 diabetes [22]. These findings may be result from the effect of eGFR decline on hyperuricemia. Unfortunately, the observational studies are unable to address this concern, more prospective interventional studies need to be performed to address this question.

A different effect of gender on progression of CKD has been reported [23-25]. However, little is known about gender difference in the effect of hyperuricemia on CKD. The present results suggest that uric acid may have independent effects on CKD prevalence more prominent in men. We found the association of hyperuricemia with CKD in males was significantly stronger than that in females, with the adjusted ORs of hyperuricemia for CKD were 2.04 (1.56-2.67) and 1.45 (1.17-1.80) for males and female, respectively. Male gender was associated with increased risk of reduced eGFR and the association of hyperuricemia with CKD was significantly stronger in males. Several observational cohort studies have also examined the gender difference in hyperuricemia predicted an increased risk of CKD progression. Interestingly, in a report from a pooled study of two separate cohort studies (the Atherosclerosis Risks in Communities and the Cardiovascular Health Study) with 13,338 participants, Weiner et al. found that baseline serum uric acid was associated with a significantly increased risk of CKD in women (OR (95\% CI): 1.10 (1.01-1.18)) but not in men (1.05 (0.96-1.1)), however, the interaction term of serum uric acid and gender was not statistically significant $(\mathrm{P}=0.8)$. Iseki $\mathrm{K}$ et al. reported that hyperuricemia was an independent risk factor for ESRD in women (adjusted HR 5.78, 95\% CI 2.3-14.4; P<0.001) but not in men (HR 2.0, 95\% CI 0.90-4.45; P=not significant) [16]. A potential explanation for these conflicted results of relationships of hyperuricemia with the prevalence or progonosis of CKD, may lie in the fact that estrogen is a uricosuric agent, and the possible mechanism for the gender difference in the hyperuricemia with the progression of CKD in cohort study might be, at least in part, linked to menopause.

Notably, animal study suggested that there is gender-divergent expression of Urat1 transporter (which is important uric acid transport and has been shown to transport uric acid into vascular smooth muscle cells)[26,27]. The male-predominant of Urat1 transporters in mouse kidneys is primarily due to stimulatory effects of androgens[27]. That imply the potential mechanism of gender hormonal influences on the handing of uric acid by kidney. However, the underlying mechanisms of gender difference of uric acid on the CKD could not be determined in the present study, and remain a matter for further investigation. 


\section{Kidney \\ Blood Pressure Research}

Kidney Blood Press Res 2012;36:98-106

\begin{tabular}{l|l}
\hline DOI: $10.1159 / 000341486$ & (c) 2012 S. Karger AG, Basel
\end{tabular}

Published online: August 29, 2012

www.karger.com/kbr

Li/Liu/Mao/Li/Dong/Liu/Lin/Chen/Wang/Johnson/Yu/Chen: Gender, Hyperuricemia and CKD

The present study has several limitations. Firstly, the cross-sectional study is naturally incapable of concluding whether hyperuricemia is a cause or a consequence of reduced renal function and CKD. Therefore, the results should be confirmed in future prospective cohort and interventional studies. Second, only one urine sample examination was obtained for each subject, which made it impossible to confirm whether the albuminuria was persistent. Results from NHANES III [28] demonstrated that using two urine tests to confirm kidney damage revealed a lower prevalence rate of stage 1 and stage 2 CKD, compared with using one urine sample. Third, use of the same cut-off value of microalbuminuria for men and women leads to higher values of prevalence for women than men. Furthermore, our study is limited by oversampled female subjects and using the modified MDRD study equation which may underestimate GFR at higher values. However, the principle aim of the present study was not to estimate the prevalence of CKD but to test the interrelationship between hyperuricemia and CKD. And to the best of our knowledge, the interaction between hyperuricemia and gender has not been studied in Chinese population-based CKD study.

In summary, hyperuricemia is independently associated with reduced renal function but not albuminuria in present studied population, and the interaction between gender and hyperuricemia with CKD was significant with a stronger association of hyperuricemia with CKD in males than in females. Our studies suggest a gender-specific linking mechanism, which emphasizing the need for further prospective studies.

\section{Acknowledgements}

This work was supported by grants from Ministry of Education, Peoples' Republic of China (No.IRT0870), from Sun Yat-sen University Clinical Research 5010 Program, from National Natural Science Foundation of China (No. 30871166 ), National Natural Science Funds for Distinguished Young Scholar (No.30925019), from Guangdong province university academic and discipline development (No. 2010-76), International Joint Research Program from Ministry of Science and Technology of China (No. 2009DFA32820 ), 973 project (2011CB50400050) to Dr Xueqing Yu. Dr. Wei Chen was supported by grants from National Natural Science Foundation of China (No.30971378), Outstanding Young Teachers Foundation of Sun Yat-sen University (09ykpy23).

\section{References}

$>1$ Levey AS, Atkins R, Coresh J, Cohen EP, Collins AJ, Eckardt KU, Nahas ME, Jaber BL, Jadoul M, Levin A, Powe NR, Rossert J, Wheeler DC, Lameire N, Eknoyan G: Chronic kidney disease as a global public health problem: approaches and initiatives-a position statement from Kidney Disease Improving Global Outcomes. Kidney Int 2007;72:247-259.

-2 Zhang L, Wang F, Wang L, Wang W, Liu B, Liu J, Chen M, He Q Liao Y, Yu X, Chen N, Zhang JE, Hu Z, Liu F, Hong D, Ma L, Liu H, Zhou X, Chen J, Pan L, Chen W, Wang W, Li X, Wang H: Prevalence of chronic kidney disease in China: a cross-sectional survey. Lancet 2012;379:815-822.

-3 Chen W, Chen W, Wang H, Dong X, Liu Q, Mao H, Tan J, Lin J, Zhou F, Luo N, He H, Johnson RJ, Zhou SF, Yu X: Prevalence and risk factors associated with chronic kidney disease in an adult population from southern China. Nephrol Dial Transplant 2009;24:1205-1212.

-4 Zhang L, Zhang P, Wang F, Zuo L, Zhou Y, Shi Y, Li G, Jiao S, Liu Z, Liang W, Wang H: Prevalence and factors associated with CKD: a population study in Beijing. Am J Kidney Dis 2008;51:373-384.

5 Chen W, Liu Q, Wang H, Chen W, Johnson RJ, Dong X, Li H, Ba S, Tan J, Luo N, Liu T, He H, Yu X: Prevalence and risk factors of chronic kidney disease: a population study in Tibetan population. Nephrol Dial Transplant. 2011;26:1592-1599.

6 Johnson RJ, Segal MS, Srinivas T, Ejaz A, Mu W, Roncal C, Sánchez-Lozada LG, Gersch M, Rodriguez-Iturbe B, Kang DH, Acosta JH: Essential hypertension, progressive renal disease, and uric acid: a pathogenetic link? J Am Soc Nephrol 2005;16:1909-1919. 


\section{Kidney \\ Blood Pressure Research}

Kidney Blood Press Res 2012;36:98-106

\begin{tabular}{l|l}
\hline DOI: $10.1159 / 000341486$ & (C) 2012 S. Karger AG, Basel
\end{tabular}

Published online: August 29, 2012

www.karger.com/kbr

Li/Liu/Mao/Li/Dong/Liu/Lin/Chen/Wang/Johnson/Yu/Chen: Gender, Hyperuricemia and CKD

-7 Weiner DE, Tighiouart H, Elsayed EF, Griffith JL, Salem DN, Levey AS: Uric acid and incident kidney disease in the community. J Am Soc Nephrol 2008;19:1204-1211.

8 Chang HY, Tung CW, Lee PH, Lei CC, Hsu YC, Chang HH, Yang HF, Lu LC, Jong MC, Chen CY, Fang KY, Chao YS, Shih YH, Lin CL: Hyperuricemia as an independent risk factor of chronic kidney disease in middle-aged and elderly population. Am J Med Sci. 2010;339:509-515.

\$ Obermayr RP, Temml C, Gutjahr G, Knechtelsdorfer M, Oberbauer R, Klauser-Braun R: Elevated uric acid increases the risk for kidney disease. J Am Soc Nephrol 2008;19:2407-2413.

10 Mok Y, Lee SJ, Kim MS, Cui W, Moon YM, Jee SH: Serum uric acid and chronic kidney disease: the Severance cohort study. Nephrol Dial Transplant 2011;27:1831-1835.

-11 Sonoda H, Takase H, Dohi Y, Kimura G: Uric acid levels predict future development of chronic kidney disease. Am J Nephrol 2011;33:352-357.

12 Chonchol M, Shlipak MG, Katz R, Sarnak MJ, Newman AB, Siscovick DS, Kestenbaum B, Carney JK, Fried LF: Relationship of uric acid with progression of kidney disease. Am J Kidney Dis 2007;50:239-247.

13 Ma YC, Zuo L, Chen JH, Luo Q Yu XQ Li Y, Xu JS, Huang SM, Wang LN, Huang W, Wang M, Xu GB, Wang HY: Modified glomerular filtration rate estimating equation for Chinese patients with chronic kidney disease. J Am Soc Nephrol 2006;17:2937-2944.

-14 Chobanian AV, Bakris GL, Black HR, Cushman WC, Green LA, Izzo JL Jr, Jones DW, Materson BJ, Oparil S, Wright JT Jr, Roccella EJ; National Heart, Lung, and Blood Institute Joint National Committee on Prevention, Detection, Evaluation, and Treatment of High Blood Pressure; National High Blood Pressure Education Program Coordinating Committee: The Seventh Report of the Joint National Committee on Prevention, Detection, Evaluation, and Treatment of High Blood Pressure: the JNC 7 report. JAMA 2003;289:2560-2572.

-15 Chuang SY, Chen JH, Yeh WT, Wu CC, Pan WH: Hyperuricemia and increased risk of ischemic heart disease in a large Chinese cohort. Int J Cardiol 2012;154:316-321.

-16 Iseki K, Ikemiya Y, Inoue T, Iseki C, Kinjo K, Takishita S: Significance of hyperuricemia as a risk factor for developing ESRD in a screened cohort. Am J Kidney Dis 2004;44:642-650.

$\checkmark 17$ Ben-Dov IZ, Kark JD: Serum uric acid is a GFR-independent long-term predictor of acute and chronic renal insufficiency: the Jerusalem Lipid Research Clinic cohort study. Nephrol Dial Transplant. 2011;26:25582566.

18 Hsu CY, Iribarren C, McCulloch CE, Darbinian J, Go AS: Risk factors for end-stage renal disease: 25-year follow-up. Arch Intern Med 2009;169:342-350.

19 See LC, Kuo CF, Chuang FH, Shen YM, Ko YS, Chen YM, Yu KH: Hyperuricemia and metabolic syndrome: associations with chronic kidney disease. Clin Rheumatol 2011;30:323-330.

20 Madero M, Sarnak MJ, Wang X, Greene T, Beck GJ, Kusek JW, Collins AJ, Levey AS, Menon V: Uric acid and long-term outcomes in CKD. Am J Kidney Dis 2009;53:796-803.

-21 Sturm G, Kollerits B, Neyer U, Ritz E, Kronenberg F: Uric acid as a risk factor for progression of non-diabetic chronic kidney disease? The Mild to Moderate Kidney Disease (MMKD) Study. Exp Gerontol 2008;43:347352.

-22 Rosolowsky ET, Ficociello LH, Maselli NJ, Niewczas MA, Binns AL, Roshan B, Warram JH, Krolewski AS: High-normal serum uric acid is associated with impaired glomerular filtration rate in nonproteinuric patients with type 1 diabetes. Clin J Am Soc Nephrol 2008;3:706-713.

-23 Neugarten J, Acharya A, Silbiger SR: Effect of gender on the progression of nondiabetic renal disease: a meta-analysis. J Am Soc Nephrol 2000;11:319-329.

24 Silbiger S, Neugarten J: The impact of gender on the progression of chronic renal disease. Am J Kidney Dis 1995;25:515-533.

25 Eriksen BO, Ingebretsen OC: The progression of chronic kidney disease: a 10-year population-based study of the effects of gender and age. Kidney Int 2006;69:375-382.

-26 Cheng X, Maher J, Chen C, Klaassen CD: Tissue distribution and ontogeny of mouse organic anion transporting polypeptides (Oatps). Drug Metab Dispos 2005;33:1062-1073.

27 Cheng X, Klaassen CD: Tissue Distribution, Ontogeny, and Hormonal Regulation of Xenobiotic Transporters in Mouse Kidneys. Drug Metab Dispos 2009;37:2178-2185.

-28 Mazzali M, Hughes J, Kim YG, Jefferson JA, Kang DH, Gordon KL, Lan HY, Kivlighn S, Johnson RJ: Elevated uric acid increases blood pressure in the rat by a novel crystal-independent mechanism. Hypertension 2001;38:1101-1106. 